\title{
Statistical dependence of auroral ionospheric currents on solar wind and geomagnetic parameters from 5 years of CHAMP satellite data
}

\author{
L. Juusola ${ }^{1}$, K. Kauristie ${ }^{1}$, O. Amm ${ }^{1}$, and P. Ritter ${ }^{2}$ \\ ${ }^{1}$ Finnish Meteorological Institute, P.O. Box 503, 00101, Finland \\ ${ }^{2}$ Helmholtz-Zentrum Potsdam, Deutsches GeoForschungsZentrum (GFZ), Telegrafenberg, 14473 Potsdam, Germany
}

Received: 2 October 2008 - Revised: 13 January 2009 - Accepted: 4 February 2009 - Published: 2 March 2009

\begin{abstract}
The effects of the solar wind dynamic pressure $(P)$, the $z$ component of the solar wind magnetic field $\left(B_{z}\right)$, the merging electric field $\left(E_{m}\right)$, season and the $K_{p}$ index on R1 and R2 field-aligned currents are studied statistically using magnetic field data from the CHAMP satellite during 2001-2005. The ionospheric and field-aligned currents are determined from the magnetic field data by the recently developed 1-D Spherical Elementary Current System (SECS) method. During southward IMF, increasing $\left|B_{z}\right|$ is observed to clearly increase the total field-aligned current, while during northward IMF, the amount of fieldaligned current remains fairly constant regardless of $\left|B_{z}\right|$. The dependence of the field-aligned current on $B_{z}$ is given by $\left|I_{r}[\mathrm{MA}]\right|=0.054 \cdot B_{z}[\mathrm{nT}]^{2}-0.34 \cdot B_{z}[\mathrm{nT}]+2.4$. With increasing $P$, the intensity of the field-aligned current is also found to increase according to $\left|I_{r}[\mathrm{MA}]\right|=0.62 \cdot P[\mathrm{nPa}]+1.6$, and the auroral oval is observed to move equatorward. Increasing $E_{m}$ produces similar behaviour, described by $\left|I_{r}[\mathrm{MA}]\right|=1.41 \cdot E_{m}[\mathrm{mV} / \mathrm{m}]+1.4$. While the absolute intensity of the ionospheric current is stronger during negative than during positive $B_{z}$, the relative change in the intensity of the currents produced by a more intense solar wind dynamic pressure is observed to be approximately the same regardless of the $B_{z}$ direction. Increasing $K_{p}$ from 0 to $\geq 5$ widens the auroral oval and moves it equatorward from between $66^{\circ}-74^{\circ}$ AACGM latitude to $59^{\circ}-71^{\circ}$ latitude. The total field aligned current as a function of $K_{p}$ is given by $\left|I_{r}[\mathrm{MA}]\right|=1.1 \cdot K_{p}+0.6$. In agreement with previous studies, total field-aligned current in the summer is found to be 1.4 times stronger than in the winter.
\end{abstract}

Keywords. Ionosphere (Auroral ionosphere; Electric fields and currents; Ionosphere-magnetosphere interactions)

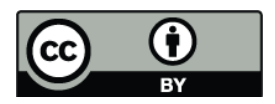

Correspondence to: L. Juusola (liisa.juusola@fmi.fi)

\section{Introduction}

A significant part of the solar wind energy that penetrates the Earth's magnetosphere is dissipated in the polar ionospheres. The most important dissipation mechanisms are Ohmic Joule heating and particle precipitation in the auroral regions (e.g., Brekke, 1997). Therefore, it is important to understand the effect the different conditions of the solar wind have on the large-scale ionospheric currents. The amount of energy consumed by Joule heating can be estimated statistically from ground-based magnetic field variations. Since Joule heating is related to Pedersen currents, while ground-based variations are mostly produced by Hall currents, understanding of how the Hall currents can describe the Pedersen currents is also needed. Satellite magnetic field measurements are well suited to studying the problem, since, unlike from groundbased magnetic field measurements, all three components of the ionospheric current density can be determined from them (Fukushima, 1976).

The main driver of ionospheric activity is the solar windmagnetosphere-ionosphere interaction. The solar wind energy enters the magnetosphere by magnetic reconnection and viscous interaction (Dungey, 1961; Axford and Hines, 1961). The electric field $(\boldsymbol{E})$ generated by the solar wind as it flows across the open magnetic field lines of the polar cap $\left(\boldsymbol{B}_{\text {geo }}\right)$ maps from the magnetosphere to the ionosphere, where it drives electric currents according to Ohm's law:

$\boldsymbol{J}=\boldsymbol{J}_{P}+\boldsymbol{J}_{H}=\Sigma_{P} \boldsymbol{E}-\Sigma_{H} \frac{\boldsymbol{E} \times \boldsymbol{B}_{\text {geo }}}{B_{\text {geo }}}$,

where $\boldsymbol{J}_{P}, \boldsymbol{J}_{H}, \Sigma_{P}$ and $\Sigma_{H}$ are the Pedersen and Hall current densities and conductances, respectively. The fieldaligned current density is related to the divergence of the horizontal current density

$j_{\|}=\nabla \cdot \boldsymbol{J}$.

Statistically, the large-scale field-aligned currents in the auroral region consist of a pair of co-centric rings, called the

Published by Copernicus Publications on behalf of the European Geosciences Union. 
region 1 (R1) and region 2 (R2) systems. The poleward R1 currents flow into the ionosphere on the dawnside and out of the ionosphere on the duskside, whereas the equatorward R2 currents have an opposite polarity at a given local time (Iijima and Potemra, 1976). While statistically the currents are strongest in the dawn and dusk sectors, the most intense currents can be found on the nightside during substorms (e.g., Kamide and Baumjohann, 1993). With increasing activity, the current system intensifies and expands to lower latitudes. The horizontal ionospheric currents consist of Pedersen currents that mainly connect the regions of upward and downward field-aligned current, and Hall currents that flow antiparallel to the plasma convection. The eastward and westward electrojets in the dusk and dawn sectors of the auroral oval, and the Harang discontinuity on the nightside, are the predominant features of this component.

Several factors can contribute to interhemispheric asymmetry of the currents. Local anomalies in the geomagnetic field are one source. Seasonal variations in local solar radiation affect the ionospheric conductivity and thereby the intensity of the currents. Due to the effect of the dipole tilt on the magnetospheric configuration, the dayside fieldaligned currents move poleward in the summer hemisphere and equatorward in the winter hemisphere, while the nightside field-aligned currents have the opposite seasonal dependence (Ohtani et al., 2005). According to the direction of the interplanetary magnetic field (IMF), reconnection on the dayside magnetopause can result in either symmetric or asymmetric convection patterns in the two hemispheres. When the IMF is southward $\left(B_{z}<0\right)$, plasma flows antisunward across the polar cap and sunward in the auroral oval, forming a two-cell convection pattern. For $B_{y} \approx 0$, the pattern is symmetric. For $B_{y}<0$, the dawn cell becomes rounder and the dusk cell crescent-shaped, whereas for $B_{y}>0$, the dusk cell becomes rounder and the dawn cell crescent-shaped in the Northern Hemisphere. In the Southern Hemisphere, for a given sign of $B_{y}$, the behaviour of the cells is reversed. When IMF is northward $\left(B_{z}>0\right)$, the convection patterns are more complex, for instance forming multiple cells (e.g., Schunk and Nagy, 2000). During strongly positive $B_{z}$, the configurations in the two hemispheres may be very different (Lu et al., 1994).

In a superposed epoch analysis, Ritter et al. (2004) showed the merging electric field $E_{m}$ (Kan and Lee, 1979) to be suitable for describing the geoeffectiveness of the solar windmagnetosphere coupling. $E_{m}$ is defined as

$E_{m}=V \sqrt{B_{y}^{2}+B_{z}^{2}} \sin ^{2}(\theta / 2)$,

where $V$ is the solar wind speed, $B_{y}$ and $B_{z}$ are the GSM $y$ and $z$ components of the IMF, and $\theta=\arctan \left(B_{y} / B_{z}\right)$ is the IMF clock angle.

The intensity of the field-aligned currents that couple magnetospheric processes to the high-latitude ionosphere is affected by the ionospheric conductivity. In the ionospheric
E-layer, ionisation of the neutral particles are caused by solar extreme ultra-violet (EUV) radiation and collisions with precipitating, energetic particles associated with the fieldaligned currents (e.g., Schunk and Nagy, 2000). The difference in the solar radiation between the winter and the summer hemispheres affects mostly conductivity on the dayside. Also particle precipitation varies with season: Using global auroral images from the Polar ultraviolet imager in the Northern Hemisphere during the winter 1996 and the summer 1997, Liou et al. (2001) have shown that nightside auroral precipitation power is suppressed and dayside power enhanced in the summer. Using a magnetohydrodynamic (MHD) simulation, Ridley (2007) demonstrated that if only the solar driven conductance changes were taken into account, the ratio between the maximum summer field-aligned current and maximum winter field-aligned current was $\sim 4$. Including a seasonally dependent auroral precipitation to increase the auroral conductance in the winter hemisphere reduced the ratio to 1.6.

Several studies have investigated the seasonal dependence of large-scale field-aligned currents using satellite-based vector magnetic field measurements. Weimer (2001) observed the field-aligned current intensities to be much stronger during summer than winter. According to Papitashvili et al. (2002), the ratio of total summer/winter field-aligned current is 1.35 and, according to Christiansen et al. (2002), 1.5-1.8. Fujii et al. (1981) and Wang et al. (2005) found the seasonal effect to be confined mainly on the dayside.

The effect of the solar wind dynamic pressure on the ionospheric dynamics has been studied by Palmroth et al. (2004). They inferred from a statistical superposed epoch analysis that during steady southward IMF, solar wind pressure pulses, as observed by ACE, increased the $A E$ index. The $A E$ index is often used as a proxy for Joule heating. During steady northward IMF, such a response was not observed. On the other hand, using a global MHD simulation, they found that Joule heating was positively correlated with the solar wind dynamic pressure both during southward and northward IMF. According to the simulation, increasing dynamic pressure increases field-aligned current, which then increases Joule heating.

Using particle precipitation data from the Defense Meteorological Satellite Program (DMSP) spacecraft, Boudouridis et al. (2003) studied the effect of large solar wind dynamic pressure increases on the location, size and intensity of the auroral oval during three events with various IMF orientation. All three events showed a change of the auroral oval location, size, and intensity in response to the pressure pulse. Most prominent changes, an increase of the auroral zone width and a decrease of the polar cap size, were observed during steady southward IMF. When the IMF turned simultaneous northward, and when it was nearly zero before the pressure enhancement, smaller responses were perceived.

In this study, we analyse statistically the effect of the $K_{p}$ index, season, the $z$ component of $\operatorname{IMF}\left(B_{z}\right)$, the solar wind 
dynamic pressure $(P)$, and the merging electric field $\left(E_{m}\right)$ on the large-scale ionospheric currents using magnetic field measurements from the CHAMP satellite. All three components of the ionospheric current density are derived from the magnetic field data using the relatively new 1-D Spherical Elementary Current System (SECS) technique (Vanhamäki et al., 2003; Juusola et al., 2006). Especially, we are interested in the differences produced by changes in $B_{z}, P$ and $E_{m}$. We start by describing how the statistical current distributions have been derived from the magnetic data (Sect. 2). Section 3 contains an overview of the data and of the differences between the Northern and the Southern Hemispheres. In Sect. 4, the data are binned with respect to activity, in Sect. 5, with respect to season, in Sect. 6, with respect to $B_{z}$ and $P$, and in Sect. 7, with respect to $E_{m}$. The last two sections contain discussion and a summary.

\section{Data processing}

In this study, the variation magnetic field measurements from the CHAMP (CHAllenging Minisatellite Payload) satellite during the years 2001-2005 have been used. On 15 July 2000, the CHAMP satellite was launched into an almost circular, near polar $\left(i=87^{\circ}\right)$ orbit with an initial altitude of $454 \mathrm{~km}$, but due to atmospheric drag, the altitude had decreased to $\sim 350 \mathrm{~km}$ by the end of 2005 . CHAMP has a period of $\sim 1.5 \mathrm{~h}$, resulting in over 15 revolutions per day, and all local time sectors are covered in 131 days. The vector magnetic field is measured by the fluxgate magnetometer on board. We have used the $1 \mathrm{~Hz}$ data, which corresponds to $\sim 7.5 \mathrm{~km}$ distance between successive measurement. The magnetic field $\left(B_{r}, B_{\theta}, B_{\phi}\right)$ was obtained by subtracting from the measurements the $\mathrm{CO} 2$ main field model (Holme et al., 2003), employed up to degree and order 14, and the ring current effect ( $D_{s t}$-correction) using the external set of coefficients of the same model.

For the analysis, the data were first converted from geographic coordinates (GEO) to geomagnetic dipole coordinates (MAG), and each orbit was divided into four overflights between $55^{\circ}-76.5^{\circ}$ northern and southern MAG latitude, as illustrated in the top panel of Fig. 1. During each overflight, the current distribution was assumed to be stationary, and 1-D (independent of longitude in some coordinate system), which is a reasonable assumption for electrojet dominated events. The full ionospheric and field-aligned current density for each the overflight was then computed using the 1-D SECS technique.

The determination of the ionospheric current density $\left(j_{r}\left[\mathrm{~A} / \mathrm{km}^{2}\right], J_{\theta}[\mathrm{A} / \mathrm{km}], J_{\phi}[\mathrm{A} / \mathrm{km}]\right)$ from the magnetic field measured by the satellite $\left(B_{r}, B_{\theta}, B_{\phi}\right)$ using the 1-D SECS method is illustrated in the bottom panel of Fig. 1: The horizontal ionospheric current density at the altitude of $100 \mathrm{~km}$ can be divided into curl-free (cf) and divergence-free (df) parts. For uniform conductances, $\boldsymbol{J}_{c f}(\theta, \phi)$ would then cor-

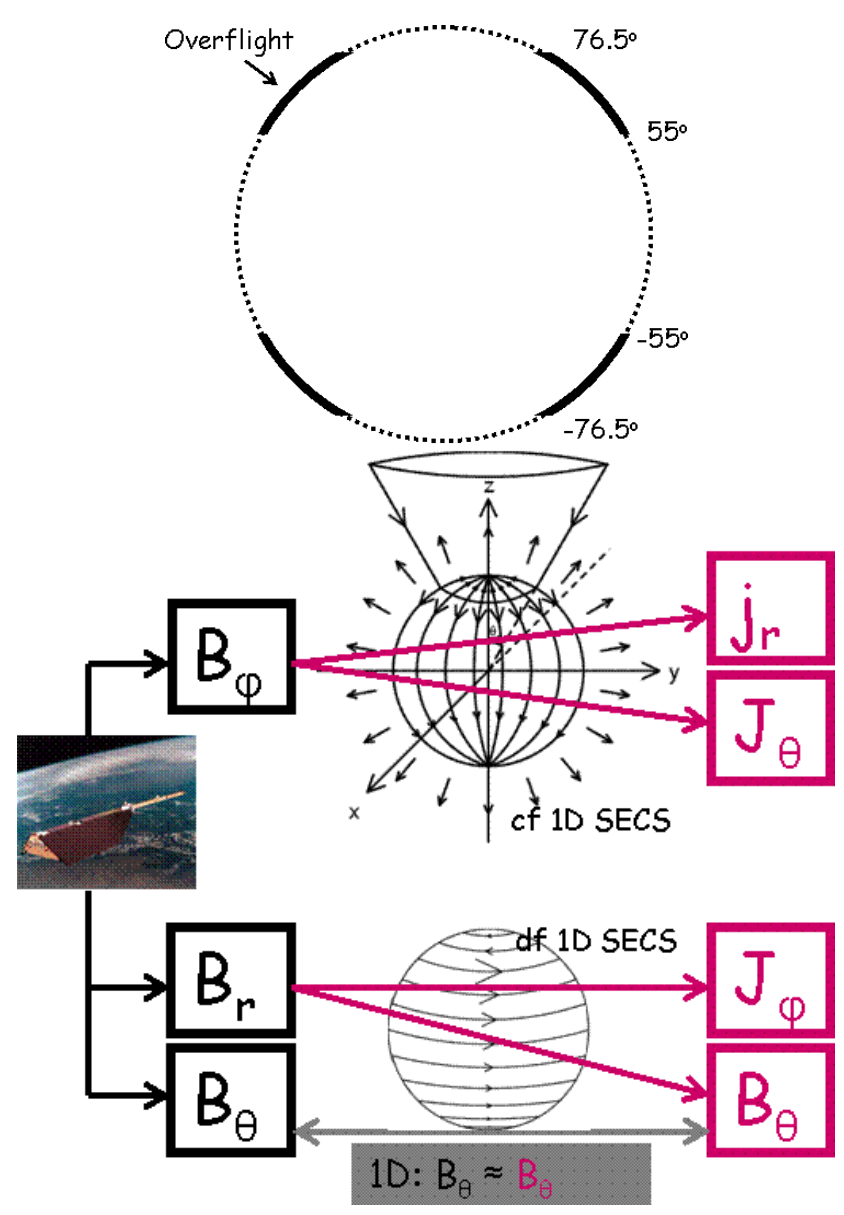

Fig. 1. Left: Division of one orbit into four overflights between $55^{\circ} \ldots 76.5^{\circ}$ and $-76.55^{\circ} \ldots-55^{\circ}$ MAG latitude. Right: Determination of the ionospheric current density $\left(j_{r}, J_{\theta}, J_{\phi}\right)$ from the magnetic field measured by a satellite $\left(B_{r}, B_{\theta}, B_{\phi}\right)$ using the 1-D SECS method (picture of CHAMP: courtesy of http://www.gfz-potsdam. de/pb1/op/champ/).

respond to Pedersen currents and $\boldsymbol{J}_{d f}(\theta, \phi)$ to Hall currents. Field-aligned currents $j_{r}(r, \theta, \phi)$ are associated with the divergence of the curl-free currents, and are assumed to flow radially. In a 1-D case, that is, when the current distribution is independent of $\phi, \boldsymbol{J}_{c f}(\theta)=\boldsymbol{J}_{\theta}(\theta) \hat{\boldsymbol{\theta}}$ and $\boldsymbol{J}_{d f}(\theta)=J_{\phi}(\theta) \hat{\boldsymbol{\phi}}$. The magnetic field caused by $j_{r}(r, \theta)$ and $\boldsymbol{J}_{\theta}(\theta)$ is $\boldsymbol{B}=B_{\phi}(r, \theta) \hat{\boldsymbol{\phi}}$ and the magnetic field caused by $J_{\phi}(\theta)$ is $\boldsymbol{B}=B_{r}(r, \theta) \hat{\boldsymbol{r}}+B_{\theta}(r, \theta) \hat{\boldsymbol{\theta}} . \quad \boldsymbol{J}_{\theta}$ and $j_{r}$ can now be computed from $B_{\phi}$ using the curl-free 1-D SECSs and similarly, $J_{\phi}$ could be determined from $B_{r}$ and $B_{\theta}$ using the divergence-free 1-D SECSs. Instead, however, we have only used $B_{r}$ and also computed $B_{\theta}$ from it. By comparing the measured and computed $B_{\theta}$, we could then determine whether the current distribution was 1-D enough that the results given by the method were reliable. In an ideal 1-D case, the computed and measured $B_{\theta}$ would be identical. 

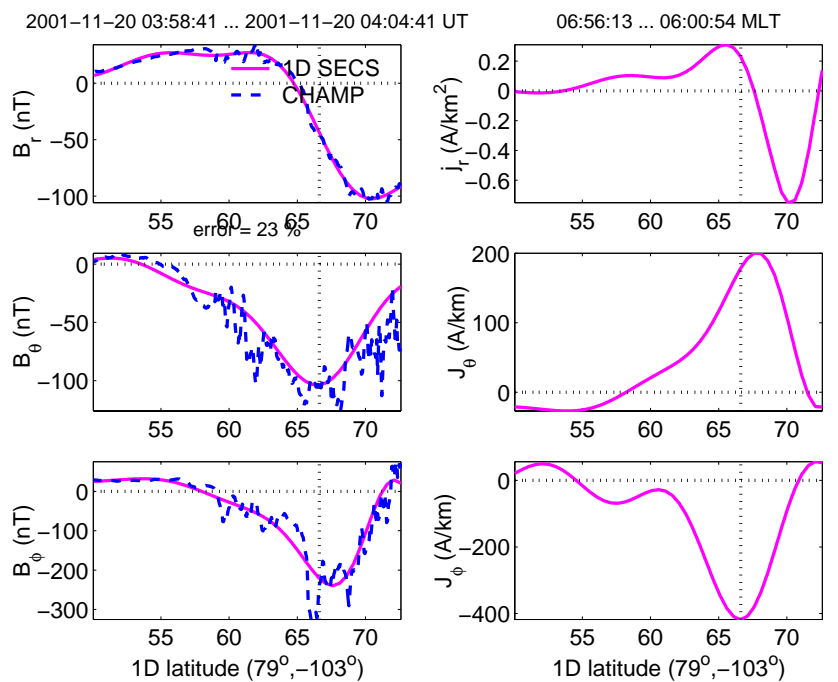

Fig. 2. Magnetic field measured by CHAMP and the ionospheric current density computed using the 1-D SECS method as a function of 1-D latitude on 20 Nov 2001 between 03:59-04:04 UT. $B_{r}$, $B_{\theta}$, and $J_{\phi}$ are determined from $B_{r}$ and $B_{\phi}, j_{r}$, and $J_{\theta}$ from $B_{\phi}$. The north pole of the 1-D coordinate system is located at $79^{\circ}$ GEO lat and $-103^{\circ}$ lon. In these coordinates, $\boldsymbol{J}_{c f}(\theta)=J_{\theta}(\theta) \hat{\boldsymbol{\theta}}$ and $\boldsymbol{J}_{d f}(\theta)=J_{\phi}(\theta) \hat{\boldsymbol{\phi}}$.

In order to optimally apply the 1-D SECS technique, the best 1-D coordinate system was determined for each overflight. The 1-D coordinate system is a spherical coordinates system similar to MAG, but its pole is displaced from the MAG pole. The optimal displacement for each overflight was determined by minimizing the difference between the measured and computed $B_{\theta}$. If such a coordinate system could be found, where the difference was small enough, the overflight was termed 1-D (see Juusola et al., 2007, for more details). An example of the application of the 1-D SECS method for one overflight is shown in Fig. 2.

After the calculation of the current density, the overflights that did not fulfil the 1-D condition were rejected. 44265 out of the total of 113700 overflights (39\%) were categorized as being 1-D. For the statistics, the current densities at $100 \mathrm{~km}$ altitude were converted from the 1-D coordinates to Altitude Adjusted Corrected Geomagnetic (AACGM; Gustafsson et al., 1992) coordinates and divided into cells of $1^{\circ}$ in AACGM latitude and $0.5 \mathrm{~h}$ in Magnetic Local Time (MLT). By experimenting, cells with less than 500 data points were rejected, and for the others, the average was computed. This was done separately for $J_{c f, \theta}, J_{c f, \phi}, J_{d f, \theta}, J_{d f, \phi}$, and $j_{r}$. In Fig. 3, for instance, the rejected data cells have been plotted in white.

To be able to compare the location and the width of the auroral oval in different bins, a simple estimate for the poleward and equatorward boundaries of the oval was needed. This was achived by first averaging the absolute value of the field-aligned current in each cell $\left(\mid I_{r}\right.$ (lat, MLT) $\left.\mid[\mathrm{A}]\right)$ over the MLT sectors 04:00-06:00 and 18:00-20:00, where the statistics were most reliable, and then determining the oval boundaries from the condition that $15.9 \%$ of $\mid I_{r}$ (lat) $\mid$ lay equatorward of the equatorward boundary of the oval and, similarly, that $15.9 \%$ of $\mid I_{r}$ (lat) $\mid$ lay poleward of the poleward boundary of the oval. For a normal or Gaussian distribution, 68.3\% of the values lie within one standard deviation from the mean, and, hence, $2 \times 15.9 \%$ of the values lie outside. The resulting oval boundaries have been marked in Fig. 3 by black arcs.

The data have been binned with respect to season, the $K_{p}$ index, solar wind dynamic pressure, IMF $B_{z}$, and the merging electric field. 1-min resolution solar wind data propagated to the magnetopause at $\sim 10 R_{E}$ from the GSFC/SPDF OMNIWeb interface at http://omniweb.gsfc.nasa.gov was used for this purpose.

The regions of missing data vary in size and location between bins. This made it more difficult to compare data between any bins, and therefore, we have only calculated $I_{r}$ from those |lat| and MLT regions where all bins that were being compared had data. The missing data regions are still slightly different, for instance, for the season- and $P$-bins. These differences may make it more difficult to compare some of the results, for instance the total field-aligned current, but the other option of equalizing all missing data regions would, on the other hand, have resulted in poorer statistics. Mainly, however, the regions over which the total fieldaligned current was integrated were similar to that shown in Fig. 3.

\section{Ionospheric currents in the Northern and in the Southern Hemispheres}

Averaged over long time-sequences, the large-scale ionospheric currents in the Northern and in the Southern Hemispheres are expected to mostly mirror each other (e.g., Schunk and Nagy, 2000). Some differences arise due to the differences in the geomagnetic field between the hemispheres, but these effects can mostly be corrected by the use of the AACGM coordinates. In order to observe any remaining effects, Fig. 3 shows the ionospheric currents in the Northern (top) and in the Southern Hemispheres (bottom), constructed from all our data during 2001-2005, as described in the previous section, with $K_{p}<6$. Averaging over such a long time sequence should smooth out any differences produced by short-period effects, leaving only the approximately constant ones.

The top left hand side panel in both plots shows the data point distribution, the top right hand side panel the fieldaligned current density (positive up), the bottom left hand side panel the $\theta$ component of the curl-free current density (north-south component, positive equatorward in the Northern Hemisphere and poleward in the Southern Hemisphere) and the bottom right hand side panel the $\phi$ component of the 

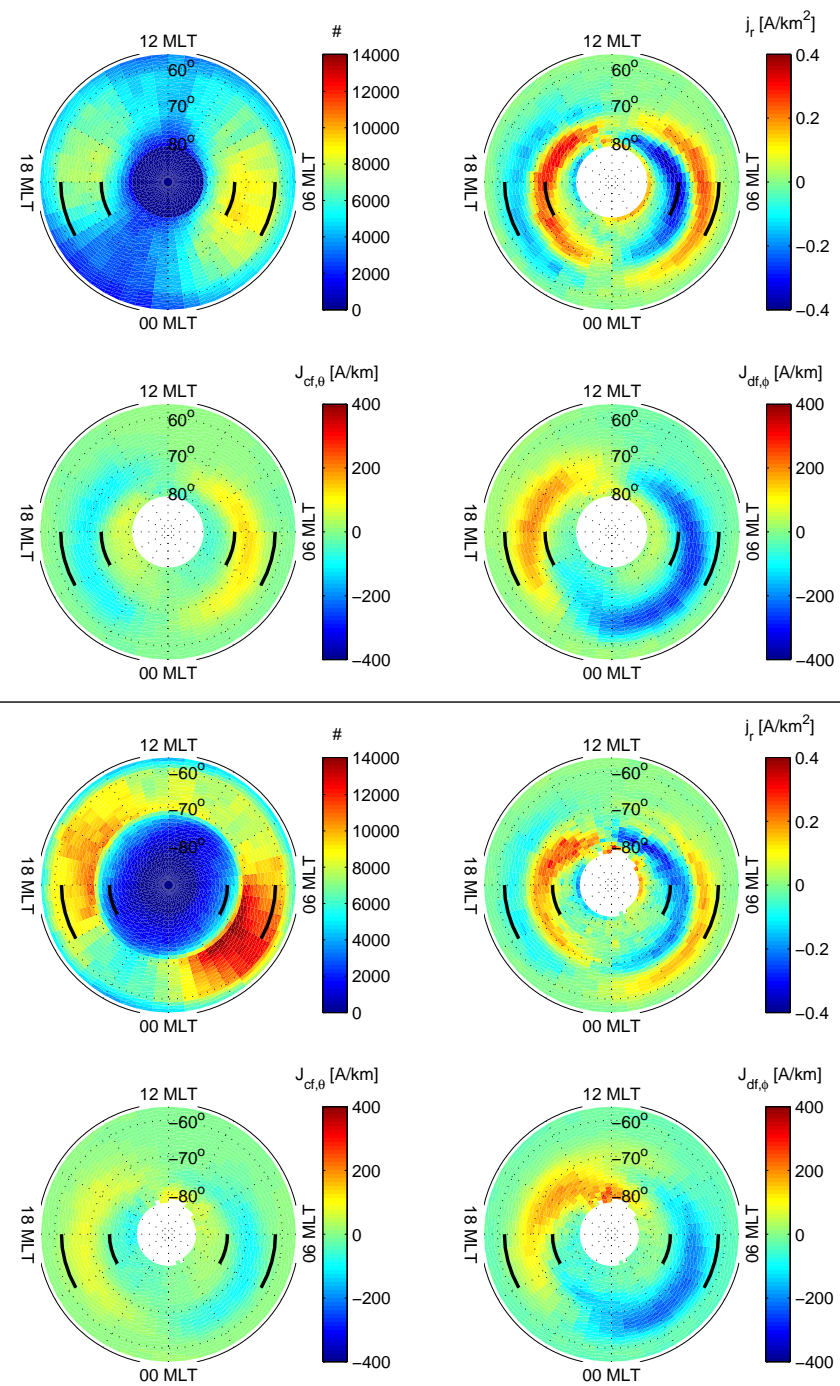

Fig. 3. Ionospheric current density in the northern (top) and in the Southern Hemisphere (bottom): Data point distribution (\#), fieldaligned current density ( $j_{r}$, positive up), $\theta$ component of the curlfree current density $\left(J_{c f, \theta}\right.$, north-south component, positive equatorward in the Northern Hemisphere and poleward in the Southern Hemisphere), and $\phi$ component of the divergence-free current density $\left(J_{d f, \phi}\right.$, east-west component, positive eastward). The black arcs denote the poleward and equatorward boundaries of the auroral oval as defined in Sect. 2.

divergence-free current density (east-west component, positive eastward). Due to the 1-D condition, which favors electrojet dominated cases, most data points were located in the dawn and dusk sectors of the oval.

In both hemispheres, $j_{r}$ displays the two co-centric rings of R1 and R2 current with the amplitude of the poleward R1 current ring stronger than that of the equatorward R2 current ring. On the dawnside, $J_{c f, \theta}$ shows that part of the downward R1 current heads equatorward towards the upward R2
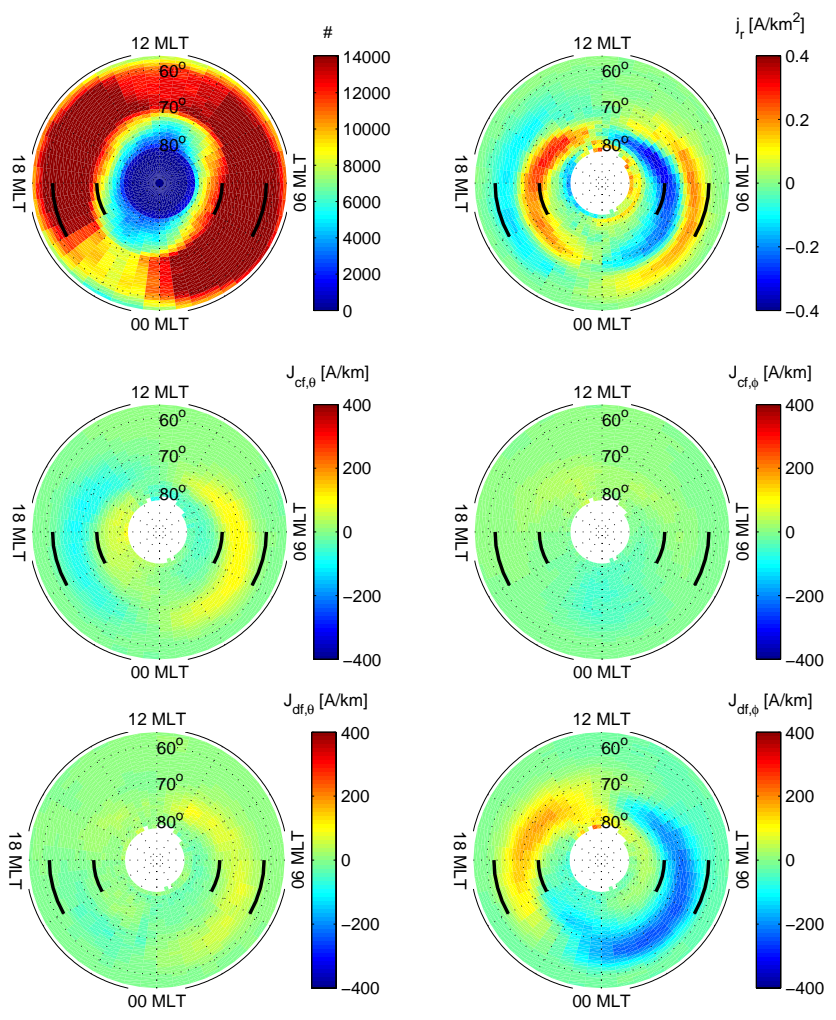

Fig. 4. Combined data from both hemispheres. $J_{c f, \phi}$ and $J_{d f, \theta}$ are also shown in addition to $J_{c f, \theta}$ and $J_{d f, \phi}$.

current, while the rest flows poleward towards the upward R1 current on the dusk side. On the duskside, the downward R2 current flows towards the upward R1 current. The antisunward electrojets in the dawn and dusk sectors of the auroral oval and the sunward return current across the polar cap are prominent in $J_{d f, \phi}$. On the nightside, where the two oppositely directed electrojets overlap, the Harang discontinuity is formed.

The black arcs in the figure denote the poleward and equatorward boundaries of the auroral oval, as defined in Sect. 2, and lie at $62^{\circ}$ and $73^{\circ}$ latitude in the Northern Hemisphere and at $-62^{\circ}$ and $-74^{\circ}$ in the Southern Hemisphere. Although the oval was determined using $j_{r}$, also the electrojets, represented by $J_{d f, \phi}$, fit well within these boundaries. Moreover, the strongest horizontal currents closing the fieldaligned currents $\left(J_{c f, \theta}\right)$ are concentrated inside this region.

Because the number of strongly disturbed overflights with $K_{p} \geq 6$ was relatively small, as can be seen in Fig. 5, including them in the average resulted in "bubbly" plots. Therefore, the condition $K_{p}<6$ was imposed here and also in the rest of the study, unless otherwise stated.

In general, the current density patterns in the two hemispheres were quite similar. The intensities were slightly stronger in the Northern Hemisphere (total integrated 


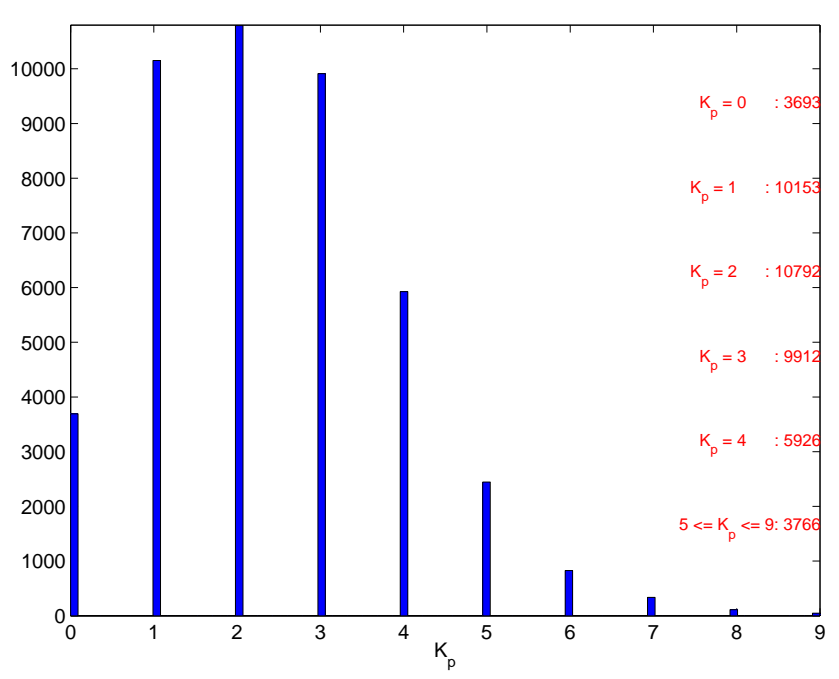

Fig. 5. Distribution of overflights as a function of $K_{p}$ and the number of overflights in the $K_{p}$-bins.

upward field-aligned current $I_{r}=+1.7$ and downward fieldaligned current $\left.I_{r}=-1.6\right)$ than in the Southern Hemisphere $\left(I_{r}=+1.3, I_{r}=-1.2\right)$, but this was most likely caused by the data selection criteria: The total number of 1-D overflights in the Northern Hemisphere was 19972, and 24270 in the Southern Hemisphere. The excess overflights in the south took place during quiet geomagnetic conditions with $K_{p}=0-2$, during which, due to the differences between the real geomagnetic field and the dipole field, the auroral oval was occasionally located poleward of the studied region between $-76.5^{\circ}$ and $-55^{\circ}$ MAG latitude. Such overflights, with practically zero magnetic field, would pass the 1-D criterion, increasing the number of 1-D overflights in the Southern Hemisphere, and decreasing the average current density there.

Since there were only minor differences between the hemispheres, the measurements from both hemispheres could be combined in order to produce more reliable statistics. This has been done in the following sections as well as in Fig. 4. This time, also $J_{c f, \phi}$ and $J_{d f, \theta}$ are shown, in addition to $J_{c f, \theta}$ and $J_{d f, \phi}$. As expected, the currents are very similar to those in Fig. 3. $J_{c f, \phi}$ is clearly weaker in intensity than the other curl-free component, $J_{c f, \theta}$. It displays mainly dawn to dusk directed currents on the dayside and on the nightside, which agree with the picture that part of the dawnside R1 currents cross the polar cap to close with the duskside R1 currents. Similarly, $J_{d f, \theta}$ is weaker than the other divergencefree component $J_{d f, \phi}$, and consistent with the picture involving the antisunward electrojets in the dawn and dusk sectors of the oval and the sunward return flow in the polar cap.

\section{Effect of the $K_{p}$ index}

A widely used proxy for geomagnetic activity is the $K_{p}$ index (Bartels et al., 1939). While by definition, increasing the index signifies the intensification and equatorward motion of the auroral oval, it is not so clear quantitatively how the current system changes as a function of $K_{p}$. In this section, this effect is studied.

Figure 5 displays the distribution of the overflights between different $K_{p}$ values. The data have been divided into six bins with $K_{p}=0, K_{p}=1, K_{p}=2, K_{p}=3, K_{p}=4$, and $K_{p} \geq 5$. Here, the values with $K_{p} \geq 6$ have also been included in the appropriate bin. The number of overflights in each bin has been written in the plot in red.

The current density binned with respect to the $K_{p}$ index is displayed in Fig. 6.

With increasing $K_{p}$, the amplitude of the current density increased and the auroral oval moved equatorward, as expected. Also, the width of the oval clearly increased.

Figure 7 shows this behaviour more quantitatively: plotted are the equatorward and poleward boundaries of the oval as well as the total field-aligned current in one hemisphere in the different bins. The lines have been fitted to the data points with the least squares method. The AACGM latitude of the poleward boundary in degrees as a function of $K_{p}$ is given by

$\mid$ lat $[\operatorname{deg}] \mid=-0.71 \cdot K_{p}+74.3$,

the location of the equatorward boundary by

$\mid$ lat $[\mathrm{deg}] \mid=-1.4 \cdot K_{p}+66.3$

and the amplitude of the total field-aligned current in MA by

$\left|I_{r}[\mathrm{MA}]\right|=1.1 \cdot K_{p}+0.6$.

Equations (4) and (5) can be combined to give the width of the auroral oval as

$\Delta \mathbf{l a t}[\operatorname{deg}]=0.69 \cdot K_{p}+8.0$.

While $K_{p}$ increased from 0 to $\geq 5$, the oval widened and moved equatorward from between $\sim 66^{\circ}-74^{\circ}$ AACGM lat to $\sim 59^{\circ}-71^{\circ}$ lat. The field-aligned currents increased by a factor of 7 .

\section{Seasonal effects}

The seasonal dependence of large-scale field-aligned currents determined from satellite-based vector magnetic field measurements has been studied extensively. Weimer (2001) used the vector magnetic field measured by the Dynamics Explorer 2 satellite to derive an empirical model that produces maps of the large-scale field-aligned currents in the high-latitude ionosphere as a function of the IMF, solar wind speed, solar wind density and dipole tilt angle. The model 

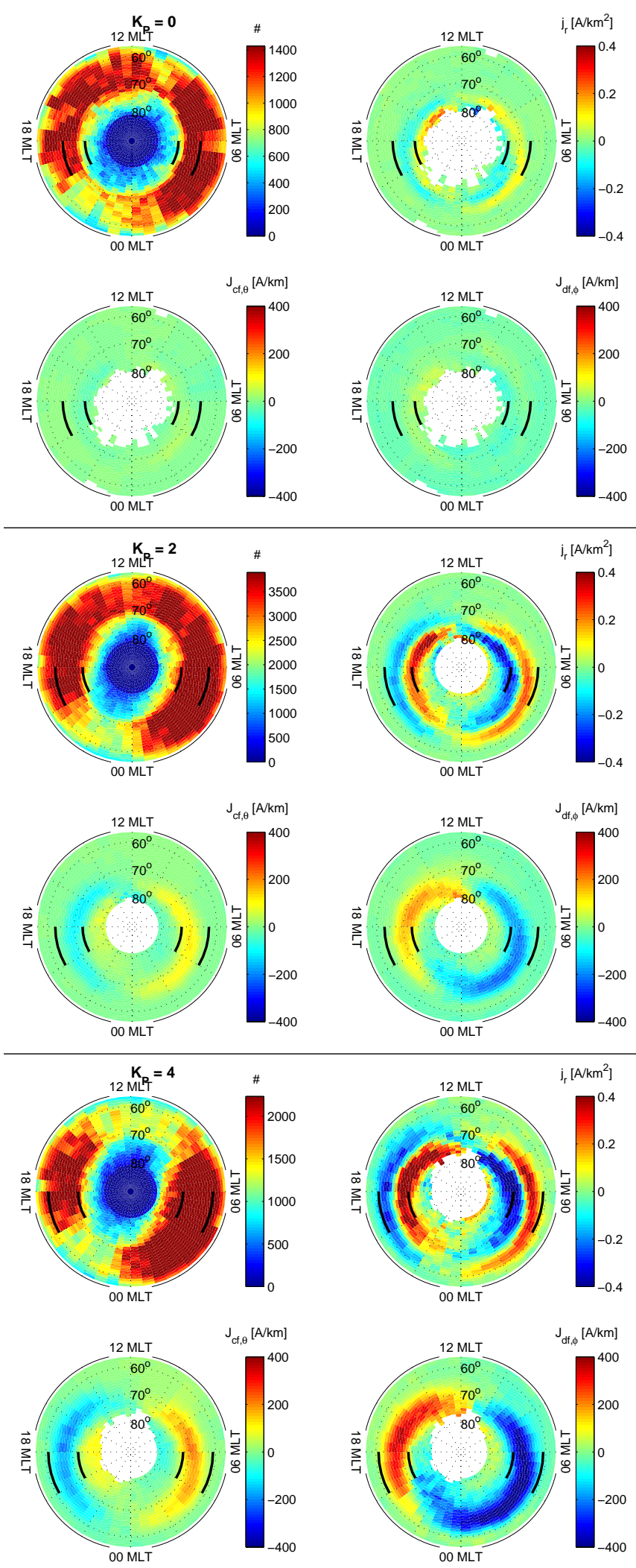

Fig. 6. Ionospheric current density binned with respect to $K_{p}$.
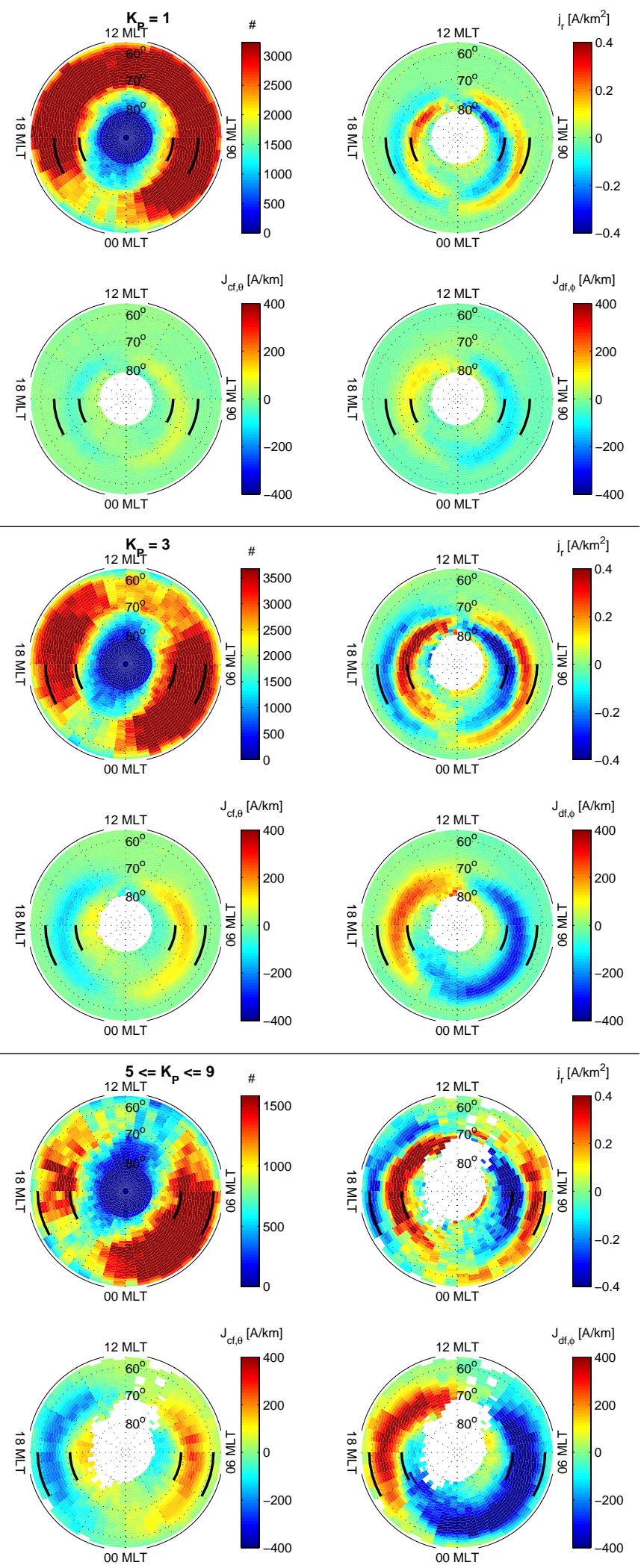

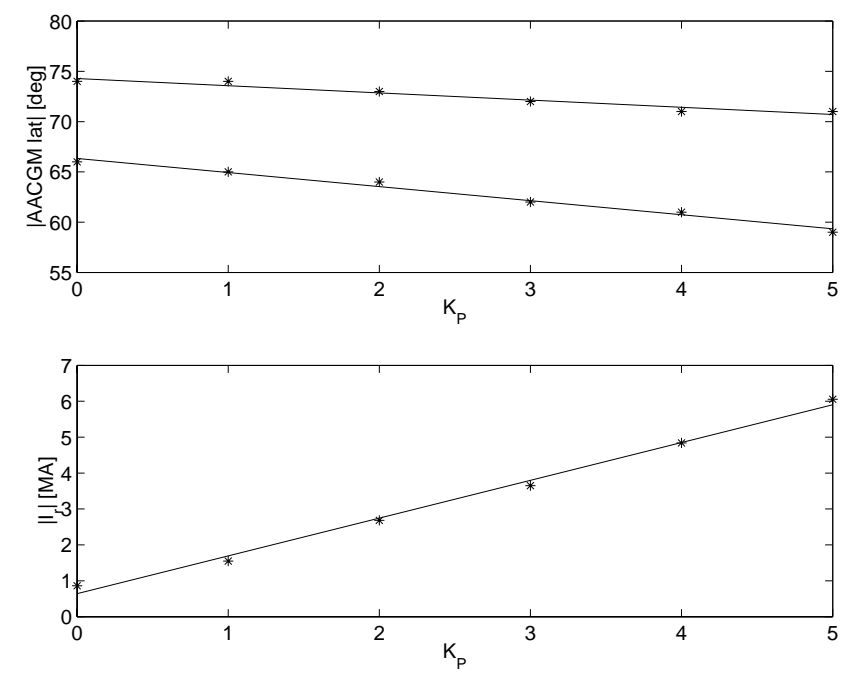

Fig. 7. The equatorward and poleward boundaries of the oval and the total field-aligned current as a function of $K_{p}$.

displayed a consistent evolution of the auroral and polar cap current systems as the IMF rotated around the circle. For negative $B_{z}$, the model included mainly the R1 and R2 systems, but for positive $B_{z}$, an additional current system appeared poleward of the R1 system. This R0 or NBZ system consisted of two regions of upward and downward fieldaligned current with a polarity opposite to the surrounding $\mathrm{R} 1$ currents. For positive $B_{y}$, the upward R1 current on the duskside wrapped through noon to become the dawnside R0 current, while the downward R1 current on the dawnside continued into the R2 current on the dawnside. The upward R0/R1 current encircled a small region of downward current, which appeared to be a remnant of the other pair in the NBZ system. Doubling the IMF magnitude intensified the currents. During summer soltice, field-aligned current intensities were much stronger than during winter solstice, and the NBZ system in particular was very prominent.

Papitashvili et al. (2002) derived a model for field-aligned currents from magnetic field measurements by the Øersted and Magsat satellites for summer, winter and equinox conditions. The magnetic field data were fitted with spherical harmonic functions and the field-aligned currents were computed using a simple 2-D curl technique. The model was parametrized by the IMF strength and direction. Using the model, Papitashvili et al. showed that the ratio of total fieldaligned summer/winter currents is $\sim 1.35$.

Christiansen et al. (2002) used the vector magnetic field measured by the Ørsted satellite from 25 August 1999 to 11 October 1999 and from 26 November 1999 to 24 January 2000 to study the seasonal variations of the highlatitude field-aligned currents. They inferred the ratio of summer/winter field-aligned currents to be about 1.5-1.8.
Fujii et al. (1981) utilized the vector magnetic field data measured by the TRIAD satellite during years 1973-1974 and 1976-1977 to determine the seasonal dependence of the large-scale field-aligned currents in the Northern Hemisphere. They found that on the dayside, the ratio of summer/winter field-aligned currents is about 2 , while on the nightside, significant differences were not perceived.

Wang et al. (2005) used 2 years of magnetic field measurements from the CHAMP satellite to investigate the fieldaligned currents in the southern polar ionosphere. They discovered that the intensity of the field-aligned currents changes with the merging electric field at all magnetic local time sectors, but with the solar radiation-induced conductivity only on the dayside.

In order to compare whether our method produces similar results, Fig. 8 shows the winter $( \pm 2$ months around winter solstice), summer ( \pm 2 months around summer solstice) and equinox (the rest of the year) current densities.

In agreement with Wang et al. (2005) and Fujii et al. (1981), the differences between the seasons in the figure were most clear on the dayside (06:00-18:00 MLT). In the winter, the currents were weaker on the dayside than on the nightside. The dayside currents intensified from winter $\left(\left|I_{r}\right|=2.5 \mathrm{MA}\right)$ to equinox $\left(\left|I_{r}\right|=2.9 \mathrm{MA}\right)$ to summer $\left(\left|I_{r}\right|=3.4 \mathrm{MA}\right)$, so that the dayside currents became stronger than the nightside currents. In agreement with Ridley (2007), Papitashvili et al. (2002) and Christiansen et al. (2002), the summer currents were found to be 1.4-times stronger than winter currents.

Considering the dayside (06:00-18:00 MLT) and nightside currents separately, the summer current turned out to be 1.7times the winter current on the dayside, but only 1.2-times the winter current on the nightside. This is in accordance with the results of Fujii et al. (1981), and confirms that the effect was indeed mostly confined on the dayside.

On the dawnside (00:00-12:00 MLT), $J_{c f, \theta}$ that connects the R1 and R2 field-aligned currents intensified fairly uniformly from winter to equinox to summer, but on the duskside (12:00-24:00 MLT), the region of strongest $J_{c f, \theta}$ and hence, the strongest field-aligned currents, shifted towards the dayside from 18:00-22:00 MLT to 14:00-22:00 MLT to 14:00-20:00 MLT. Table 1 lists separately the dawnside and duskside R1 (negative $I_{r}$ on the dawnside and positive $I_{r}$ on the duskside) and R2 (positive $I_{r}$ on the dawnside and negative $I_{r}$ on the duskside) currents.

During all seasons, the majority of the R1 current was closed by the oppositely directed R2 current on the same side. In the winter, the net current on the dawnside (-0.1 MA) balanced the net current on the duskside $(+0.1 \mathrm{MA})$, which indicates that about $15 \%$ of the dawnside current crossed over to the duskside. During the equinox and in the summer, on the other hand, the net currents on the dawnside $(+0.1 \mathrm{MA},+0.1 \mathrm{MA})$ and on the duskside $(+0.2 \mathrm{MA},+0.1 \mathrm{MA})$ were both positive, indicating that they might have been closed somewhere else, possibly in the 

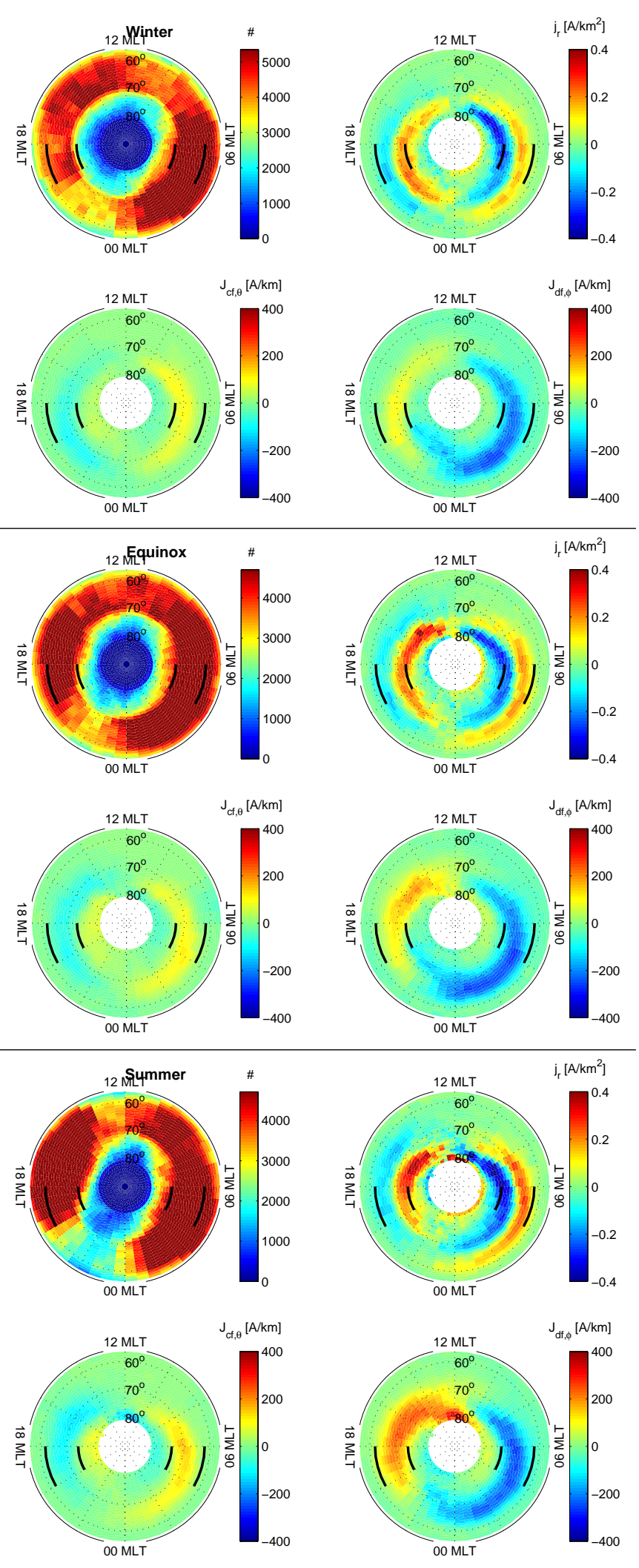

Fig. 8. Ionospheric current density binned with respect to season.
Table 1. Dawnside (00:00-12:00 MLT) and duskside (12:0024:00 MLT) R1 (negative $I_{r}$ on the dawnside and positive $I_{r}$ on the duskside) and R2 (positive $I_{r}$ on the dawnside and negative $I_{r}$ on the duskside) currents in MA.

\begin{tabular}{lllll}
\hline & Dawn R1 & Dawn R2 & Dusk R1 & Dusk R2 \\
\hline Winter & -0.7 & 0.6 & 0.6 & -0.5 \\
Equinox & -0.7 & 0.8 & 0.8 & -0.6 \\
Summer & -0.9 & 1 & 0.8 & -0.7 \\
\hline
\end{tabular}

polar cap by the R0 currents. This would be in agreement with the result of Weimer (2001) that the R0 current system is very prominent in the summer.

\section{Solar wind dynamic pressure effects vs. IMF $B_{z}$ effects}

The two top left hand side panels of Fig. 9 display the distribution of the overflights as a function of the solar wind dynamic pressure $(P)$ and the $z$ component of the $\operatorname{IMF}\left(B_{z}\right)$. The red lines in the plots display the bin boundaries and the number of overflights in each bin is written in red. The bins were chosen so that an approximately equal number of overflights would fall into each. The right hand side panels display the equatorward and poleward boundaries of the auroral oval and the total field-aligned current. The $P$ and $B_{z}$ values on the $x$-axis are the medians for the bins.

With increasing $P$, also the intensity of the field-aligned current increased and both the poleward and the equatorward boundaries of the oval moved equatorward. Lines fitted to the points gave the AACGM lat of the poleward boundary of the oval in degrees as a function of $P$ in $\mathrm{nPa}$ as

$|\operatorname{lat}[\mathrm{deg}]|=-0.57 \cdot P[\mathrm{nPa}]+74.4$,

the equatorward boundary as

$|\operatorname{lat}[\operatorname{deg}]|=-0.59 \cdot P[\mathrm{nPa}]+63.6$

and the amplitude of the total field-aligned current in MA as

$\left|I_{r}[\mathrm{MA}]\right|=0.62 \cdot P[\mathrm{nPa}]+1.6$.

There was only little variation in the intensity of the fieldaligned current for positive and zero $B_{z}$, but for negative $B_{z}$, the intensity of the field-aligned current clearly increased with increasing amplitude of $B_{z}$. A polynomial of degree 2 was fitted to the data in the least-squares sense, giving the amplitude of the total field-aligned current in MA as a function of $B_{z}$ in $\mathrm{nT}$ as

$\left|I_{r}[\mathrm{MA}]\right|=0.054 \cdot B_{z}[\mathrm{nT}]^{2}-0.34 \cdot B_{z}[\mathrm{nT}]+2.4$.

During negative $B_{z}$, the auroral oval was shifted slightly southward from its zero $B_{z}$ location, and during positive $B_{z}$, the poleward boundary of the oval was shifted poleward. 

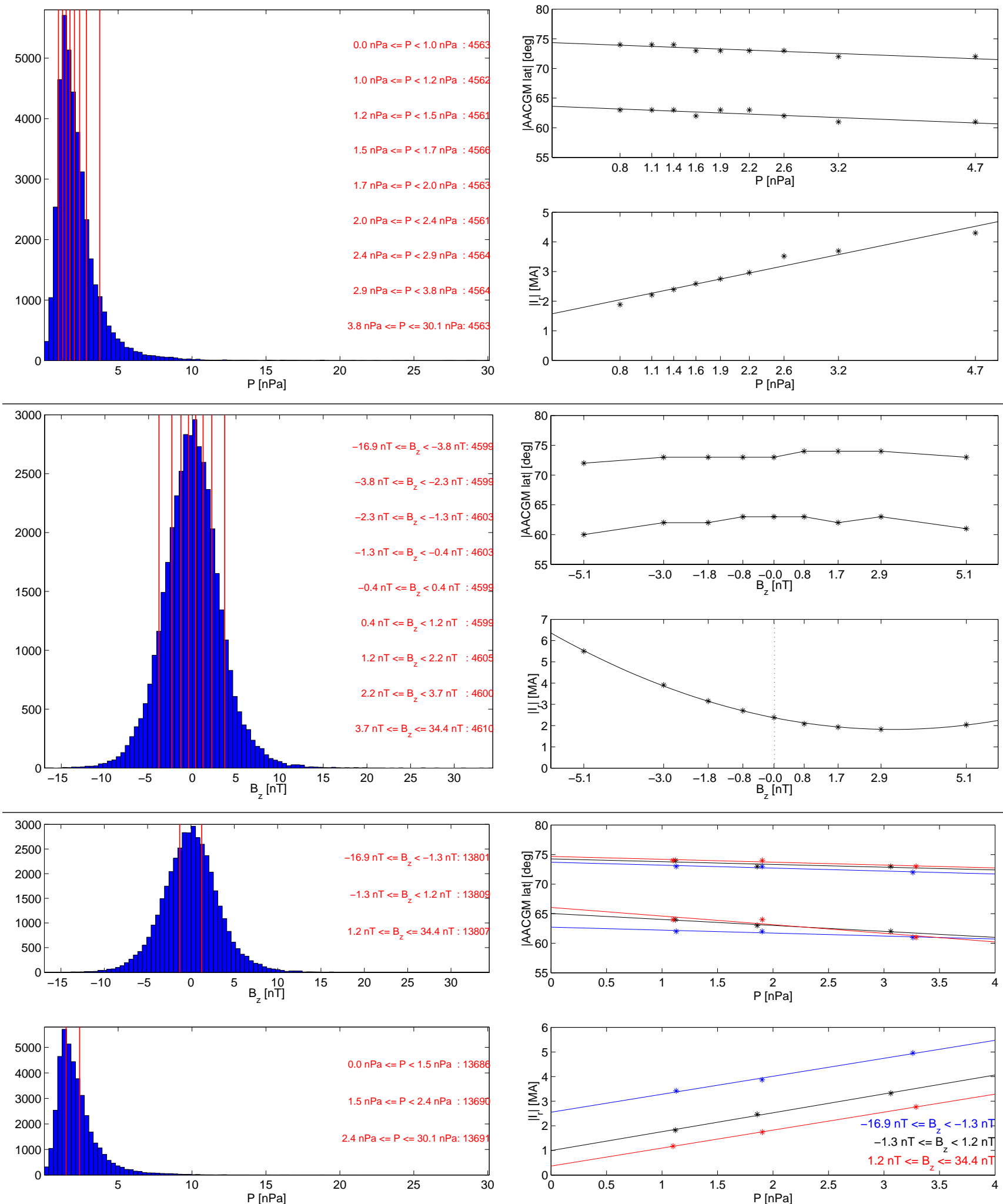

Fig. 9. Left: Distribution of the overflights as a function of the solar wind dynamic pressure $P$ and the $z$ component of the IMF $\left(B_{z}\right)$. The red lines display the bin boundaries (nine bins for the top and middle panels and three for the bottom panels) and the number of overflights in each bin is written in red. Right: The equatorward and poleward boundaries of the auroral oval and the total field-aligned current as a function of $P$ (top), $B_{z}$ (middle) and $P$ for negative, close to zero and positive $B_{z}$ (bottom). 
The bottom panels of Fig. 9 show the data binned with respect to both $B_{z}$ and $P$. There are three bins for $B_{z}$, and the values in those bins have further been divided into three bins with respect to $P$. The left hand side panel shows the distribution of overflights into the three $B_{z}$ and $P$ bins, separately. The right hand side panel displays the equatorward and poleward boundaries of the auroral oval and the total field-aligned current as a function of $P$. The three $B_{z}$ bins are denoted by the colors (negative $B_{z}$, zero $B_{z}$, positive $B_{z}$ ).

In agreement with the global MHD simulation results of Palmroth et al. (2004), our results indicate that regardless of the IMF direction, there is a positive correlation between the solar wind dynamic pressure and the intensity of the ionospheric currents. Although the relative response is not weaker for positive than for negative IMF (the fitted lines have slopes $0.73,0.77$, and 0.73 ), the absolute intensity of the currents is clearly stronger for negative than for zero or positive IMF (the offsets of the lines are 2.6 MA, 1.0 MA, and 0.4 MA). Therefore, the most intense currents were obtained with negative $B_{z}$ and high dynamic pressure. For the negative $B_{z}$ and maximum $P$-bin, the currents were 4.2 times stronger than for the positive $B_{z}$ and minimum $P$-bin.

\section{Effects of the merging electric field}

The left hand side panel of Fig. 10 shows the distribution of the overflights as a function of the merging electric field $E_{m}$. The red lines in the plot again display the bin boundaries and the number of overflights in each bin is written in red. As in the previous section, also here the bins were chosen so that an approximately equal number of overflights would fall into each. The right hand side panel displays the equatorward and poleward boundaries of the auroral oval and the total fieldaligned current. The $E_{m}$ values on the $x$-axis are the medians for the bins.

Lines fitted to the points give the AACGM lat of the poleward boundary of the oval in degrees as a function of $E_{m}$ in $\mathrm{mV} / \mathrm{m}$ as

$|\operatorname{lat}[\mathrm{deg}]|=-0.80 \cdot E_{m}[\mathrm{mV} / \mathrm{m}]+74.1$,

the equatorward boundary as

$|\operatorname{lat}[\mathrm{deg}]|=-0.82 \cdot E_{m}[\mathrm{mV} / \mathrm{m}]+63.1$

and the amplitude of the total field-aligned current in MA as

$\left|I_{r}[\mathrm{MA}]\right|=1.41 \cdot E_{m}[\mathrm{mV} / \mathrm{m}]+1.4$.

The behaviour of the locations of the poleward and equatorward boundaries of the oval and $\left|I_{r}\right|$ as a function of $P$ and $E_{m}$ resemble each other closely. With increasing values of both, the auroral oval moves equatorward and $\left|I_{r}\right|$ intensifies linearly. For positive $B_{z}$, on the other hand, $\left|I_{r}\right|$ is relatively independent on the magnitude of $B_{z}$, remaining around $2 \mathrm{MA}$, whereas for negative $B_{z}$, the intensity of $\left|I_{r}\right|$ increases with increasing $B_{z}$ magnitude.

\section{Discussion}

The solar wind energy enters the magnetosphere by magnetic reconnection and viscous interaction (Dungey, 1961; Axford and Hines, 1961), but the location where reconnection takes place on the dayside magnetopause still remains unresolved. There are two main hypothesis that predict the effect of the IMF direction on the location: According to the component reconnection hypothesis (Sonnerup, 1974), reconnection is most likely to occur on a line passing through the subsolar point, where the solar wind dynamic pressure is most intense. The angle between the magnetosheath and the geomagnetic field is less relevant: the antiparallel components of the fields are reconnected regardless of the presence of any parallel components. In contrast, the antiparallel reconnection hypothesis (Luhmann et al., 1984) states that the presence of parallel components is enough to prevent reconnection, which implies that reconnection can only take place in those regions on the magnetopause where the magnetosheath and geomagnetic fields are oppositely directed. Therefore, any IMF orientation can produce reconnection, provided that there is a region where the two fields are antiparallel, and that there is sufficient plasma convection towards that region to bring the two field configurations in contact.

During negative IMF $B_{z}$ and zero $B_{y}$, both hypothesis predict a uniform reconnection line at the equatorial plane, but with increasing $B_{y}$, the antiparallel reconnection line breaks and the ends move away from equator toward the cusps, while the component reconnection line remains uniform and is merely tilted. During positive $B_{z}$, parallel reconnection is predicted to take place tailward of the cusps, while component reconnection occurs mostly due to $B_{y}$.

Since the reconnection rate is related to the Alfvén velocity of the inflowing plasma $\left(V_{A}=B / \sqrt{\mu_{0} \rho}, \rho\right.$ is the mass density), reconnection at the magnetopause could be enhanced by increasing IMF $B$. According to both the component and antiparallel reconnection hypothesis, intensifying negative IMF $B_{z}$, which implies either increasing $B$ or rotation of the IMF vector towards a more southward orientation, generally increases the reconnection rate. During positive $B_{z}$, component reconnection is caused by $B_{y}$, which would imply that the intensity of $B_{z}$ has no effect on the reconnection rate. According to the antiparallel hypothesis, on the other hand, during positive IMF $B_{z}$, reconnection occurs tailward of the cusps. While the reconnection rate should then depend on the $B_{z}$ amplitude, the ionospheric signatures would be mostly confined to high $\left(>80^{\circ}\right)$ latitudes (e.g., Stauning, 2002), which have not been included in our study. Therefore, our results, according to which there was very little variation in the auroral ionospheric field-aligned current intensity during positive and zero $B_{z}$, while during negative $B_{z}$, the intensity increased with the increasing amplitude of $B_{z}$, are in agreement with both hypothesis.

The polar cap size is a measure of the magnetic flux within the tail lobes. When the reconnection rate at the 

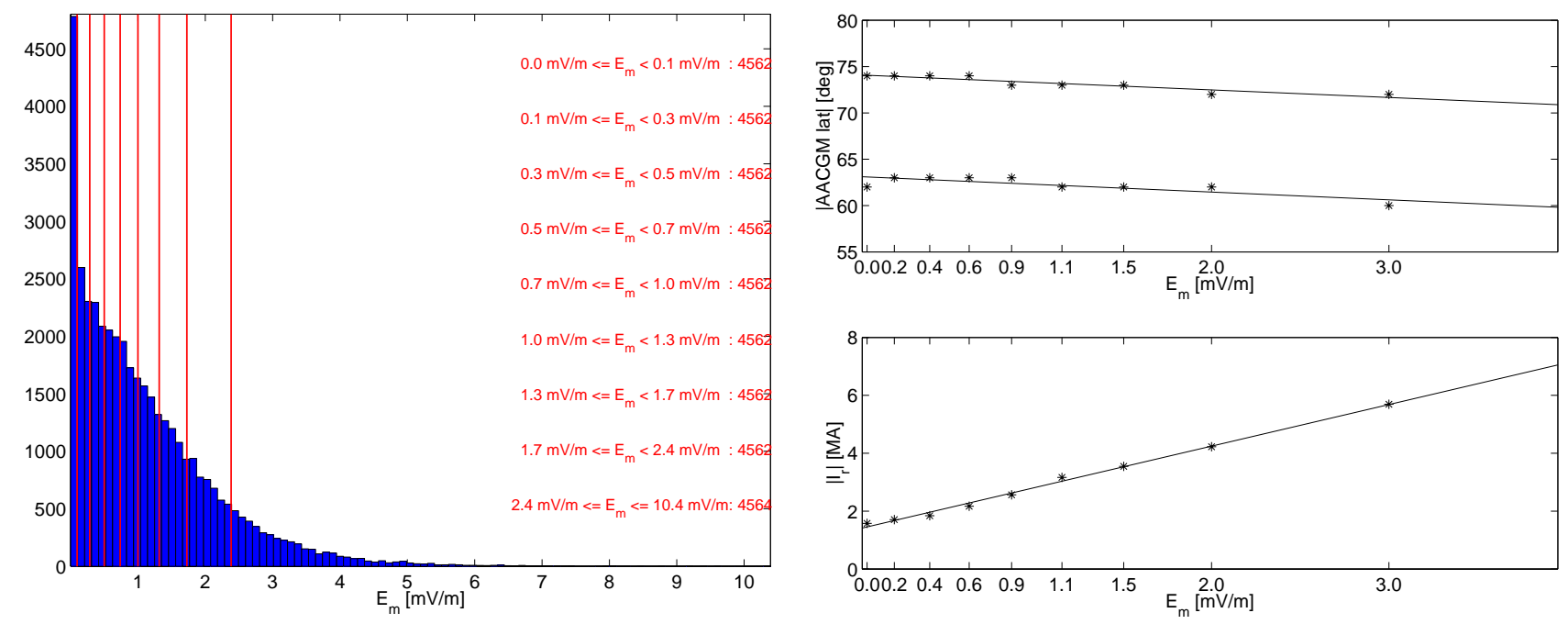

Fig. 10. Left: Distribution of the overflights as a function of the merging electric field $\left(E_{m}\right)$. The red lines display the bin boundaries and the number of overflights in each bin is written in red. Right: The equatorward and poleward boundaries of the auroral oval and the total field-aligned current as a function of $E_{m}$.

magnetopause exceeds that in the tail, the boundary between the open and closed field lines moves equatorward. The electric field associated with the solar wind plasma flow across these reconnected open field lines of the polar cap $(\boldsymbol{E}=-\boldsymbol{V} \times \boldsymbol{B}, \boldsymbol{V}$ is the solar wind velocity and $\boldsymbol{B}$ the IMF) is mapped down to the ionosphere along the geomagnetic field lines. According to Eqs. (1) and (2), the Pedersen, Hall and field-aligned current densities are then all affected by $\boldsymbol{E}$, which could be enhanced by increasing $B, P=\rho V^{2}$ or $E_{m}=V \sqrt{B_{y}^{2}+B_{z}^{2}} \sin ^{2}(\theta / 2)$.

Since $E_{m}$ takes into account both the IMF direction and magnitude and the solar wind speed, it could be expected to describe the solar wind-magnetosphere coupling better than either $B_{z}$ or $P$. Indeed, in Figs 9 and 10, the most intense currents can be found in the high $E_{m}$-bin.

\section{Summary}

Magnetic field measurements from the CHAMP satellite during years 2001-2005 have been used to derive statistical maps of ionospheric currents as a function of the AACGM latitude and MLT. The effects of the $K_{p}$ index, season, the $z$ component of the IMF $\left(B_{z}\right)$, the solar wind dynamic pressure $(P)$, and the merging electric field $\left(E_{m}\right)$ on the large-scale ionospheric currents have been studied.

The ionospheric currents in the Northern and in the Southern Hemispheres were found to differ only slightly when averaged over long time periods, which meant that the data from both hemispheres could be combined in order to improve the statistics. Between 04:00-06:00 and 18:00-
20:00 MLT, the oval was found to be located between $62^{\circ}-$ $73^{\circ}$ latitude, on average.

Increasing the $K_{p}$ index from 0 to $\geq 5$ intensified the total field-aligned current by a factor of 7 . The auroral oval widened and moved equatorward from between $66^{\circ}-74^{\circ}$ AACGM lat to $59^{\circ}-71^{\circ}$ lat. Simple expressions describing the locations of the poleward (Eq. 4) and equatorward boundary of the oval (Eq. 5) as well as the total field-aligned current (Eq. 6) were determined.

Seasonal effects on the currents were found to be most prominent on the dayside. In agreement with previous studies, total field-aligned current in the summer was found to be 1.4 times stronger than in the winter. On the dayside (06:0018:00 MLT), the ratio was 1.7 and on the nightside, 1.2.

With increasing $P$ or $E_{m}$, the poleward and equatorward boundaries of the auroral oval moved equatorward and the total field-aligned current intensified linearly (Eqs. 10 and 14). There was only little variation in the intensity of the fieldaligned current for positive and zero $B_{z}$, but for negative $B_{z}$, the intensity clearly increased with increasing amplitude of $B_{z}$. Equation (11) was derived to describe the dependence of the total field-aligned current on $B_{z}$. Thus, the most intense currents were obtained with negative $B_{z}$ and high dynamic pressure. For the negative $B_{z}$ and maximum $P$-bin, the currents were 4.2 times stronger than for the positive $B_{z}$ and minimum $P$-bin.

While the absolute intensity of the ionospheric currents was stronger during southward than during northward IMF, the relative change in the intensity of the currents produced by a more intense solar wind dynamic pressure was observed to be approximately the same regardless of the IMF direction. 
Acknowledgements. The operational support of the CHAMP mission by the German Aerospace Center (DLR) and the financial support for the data processing by the Federal Ministry of Education (BMBF), as part of the Geotechnology Programme, are gratefully acknowledged. The OMNI data were obtained from the GSFC/SPDF OMNIWeb interface at http://omniweb.gsfc.nasa.gov. The work of L. Juusola was supported by the Finnish Graduate School in Electromagnetics and the Academy of Finland (project no. 121289). The authors thank S. Hassinen for technical assistance.

Topical Editor M. Pinnock thanks V. Papitashvili for his help in evaluating this paper.

\section{References}

Axford, W. I. and Hines, C. O.: A unifying theory of high-latitude geophysical phenomena and geomagnetic storms, Can. J. Phys., 39, 1433-1464, 1961.

Bartels, J., Heck, N. H., and Johnston, H. F.: The three-hourrange index measuring geomagnetic activity, Terr. Magn. Atmos. Electr., 44, 411-454, 1939.

Boudouridis, A., Zesta, E., and Lyons, L. R.: Effect of solar wind pressure pulses on the size and strength of the auroral oval, J. Geophys. Res., 108, 8012, doi:10.1029/2002JA009373, 2003.

Brekke, A.: Physics of the Upper Polar Atmosphere, Wiley-Praxis Series in Atmospheric Physics, John Wiley and Sons, New York, 1997.

Christiansen, F., Papitashvili, V. O., and Neubert, T.: Seasonal variations of high-latitude field-aligned currents inferred from Ørsted and Magsat observations, J. Geophys. Res., 107, 1029, doi:10.1029/2001JA900104, 2002.

Dungey, J. W.: Interplanetary Magnetic Field and the Auroral Zones, Phys. Rev. Lett., 6, 47-48, 1961.

Fujii, R., Iijima, T., Potemra, T. A., and Sugiura, M.: Seasonal Dependence of Large-Scale Birkeland Currents, Geophys. Res. Lett., 8, 1103-1106, 1981.

Fukushima, N.: Generalized theorem for no ground magnetic effect of vertical currents connected with Pedersen currents in the uniform-conductivity ionosphere, Rep. Ionos. Space Res. Japan, 30, 35-40, 1976.

Gustafsson, G., Papitashvili, N. E., and Papitashvili, V.: A revised corrected geomagnetic coordinate system for Epochs 1985 and 1990, J. Atmos. Terr. Phys., 54, 1609-1631, 1992.

Holme, R., Olsen, N., Rother, M., and Lühr, H.: CO2 - A CHAMP magnetic field model, 220-225, First CHAMP Mission Results for Gravity, Magnetic and Atmospheric Studies edited by C. Reigber and H. Lühr and P. Schwintzer, Springer, Berlin, 2003.

Iijima, T. and Potemra, T. A.: The Amplitude Distribution of FieldAligned Currents at Northern High Latitudes Observed by Triad, J. Geophys. Res., 81, 2165-2174, 1976.

Juusola, L., Amm, O., and Viljanen, A.: One-dimensional spherical elementary current systems and their use for determining ionospheric currents from satellite measurements, Earth, Planets and Space, 58, 667-678, 2006.

Juusola, L., Amm, O., Kauristie, K., and Viljanen, A.: A model for estimating the relation between the Hall to Pedersen conductance ratio and ground magnetic data derived from CHAMP satellite statistics, Ann. Geophys., 25, 721-736, 2007,

http://www.ann-geophys.net/25/721/2007/.
Kamide, Y. and Baumjohann, W.: Magnetosphere-Ionosphere Coupling, Springer-Verlag, Berlin Heidelberg, 1993.

Kan, J. R. and Lee, L. C.: Energy Coupling Function and Solar Wind-Magnetosphere Dynamo, Geophys. Res. Lett., 6, 577-580, 1979.

Liou, K., Newell, P. T., and Meng, C.-I.: Seasonal effects on auroral particle acceleration and precipitation, J. Geophys. Res., 106, 5531-5542, 2001.

Lu, G., Richmond, A. D., Emery, B. A., Reiff, P. H., de la Beaujardière, O., Rich, F. J., Denig, W. F., Kroehl, H. W., Lyons, L. R., Ruohoniemi, J. M., Friis-Christensen, E., Opgenoorth, H., Persson, M. A. L., Lepping, R. P., Rodger, A. S., Hughes, T., McEwin, A., Dennis, S., Morris, R., Burns, G., and Tomlinson, L.: Interhemispheric Asymmetry of the High-Latitude Ionospheric Convection Pattern, J. Geophys. Res., 99, 6491-6510, 1994.

Luhmann, J. G., Walker, R. J., Russell, C. T., Crooker, N. U., Spreiter, J. R., and Stahara, S. S.: Patterns of Potential Magnetic Field Merging Sites on the Dayside Magnetopause, J. Geophys. Res., 89, 1739-1742, 1984.

Ohtani, S., Ueno, G., Higuchi, T., and Kawano, H.: Annual and semiannual variations of the location and intensity of large-scale field-aligned currents, J. Geophys. Res., 110, A01216, doi:10. 1029/2004JA010634, 2005.

Palmroth, M., Pulkkinen, T. I., Janhunen, P., McComas, D. J., Smith, C. W., and Koskinen, H. E. J.: Role of solar wind dynamic pressure in driving ionospheric Joule heating, J. Geophys. Res., 109, A11302, doi:10.1029/2004JA010529, 2004.

Papitashvili, V. O., Christiansen, F., and Neubert, T.: A new model of field-aligned currents derived from high-precision satellite magnetic field data, Geophys. Res. Lett., 29, 1683, doi:10.1029/ 2001GL014207, 2002.

Ridley, A. J.: Effects of seasonal changes in the ionospheric conductances on magnetospheric field-aligned currents, Geophys. Res. Lett., 34, L05101, doi:10.1029/2006GL028444, 2007.

Ritter, P., Lühr, H., Maus, S., and Viljanen, A.: High-latitude ionospheric currents during very quiet times: their characteristics and predictability, Ann. Geophys., 22, 2001-2014, 2004, http://www.ann-geophys.net/22/2001/2004/.

Schunk, R. W. and Nagy, A. F.: Ionospheres - Physics, Plasma Physics, and Chemistry, Cambridge Univ. Press, 2000.

Sonnerup, B. U. O.: Magnetopause reconnection rate, J. Geophys. Res., 79, 1546-1549, 1974.

Stauning, P.: Field-aligned ionospheric current systems observed from Magsat and Oersted satellites during northward IMF, Geophys. Res. Lett., 29, 8005, doi:10.1029/2001GL013961, 2002.

Vanhamäki, H., Amm, O., and Viljanen, A.: 1-Dimensional upward continuation of the ground magnetic field disturbance using spherical elementary current systems, Earth Planets Space, 55, 613-625, 2003.

Wang, H., Lühr, H., and Ma, S. Y.: Solar zenith angle and merging electric field control of field-aligned currents: A statistical study of the Southern Hemisphere, J. Geophys. Res., 110, A03306, doi: 10.1029/2004JA010530, 2005.

Weimer, D. R.: Maps of ionospheric field-aligned currents as a function of the interplanetary magnetic field derived from Dynamics Explorer 2 data, J. Geophys. Res., 106, 12889-12902, 2001. 